\title{
Obstructive sleep apnoea in acute coronary syndrome: the invisible threat?
}

\author{
Michael Arzt ${ }^{1}$, Andrea Hetzenecker ${ }^{2}$ and Patrick Lévy ${ }^{3}$ \\ Affiliations: ${ }^{1}$ Centre of Sleep Medicine, Dept of Internal Medicine II, University Medical Centre Regensburg, \\ Regensburg, Germany. ${ }^{2}$ Centre for Pneumology, Donaustauf Hospital, Donaustauf, Germany. ${ }^{3}$ Univ. Grenoble \\ Alpes, INSERM, Grenoble Alpes University Hospital, HP2 Laboratory and Sleep Laboratory, Grenoble, France.
}

Correspondence: Michael Arzt, Centre of Sleep Medicine, Dept of Internal Medicine II, University Medical Centre Regensburg, Franz-Josef-Strauss Allee 11, 93042 Regensburg, Germany. E-mail: Michael.arzt@ukr.de

@ERSpublications

In patients with acute coronary syndrome polygraphy monitoring is required to detect sleep-disordered breathing http://ow.ly/JjZi309czta

Cite this article as: Arzt M, Hetzenecker A, Lévy P. Obstructive sleep apnoea in acute coronary syndrome: the invisible threat? Eur Respir J 2017; 49: 1602539 [https://doi.org/10.1183/13993003.02539-2016].

Worldwide, coronary artery disease (CAD) is the single most common cause of death [1]. Over seven million people every year die from CAD, accounting for $13.2 \%$ of all deaths $[1,2]$. The presentation of acute coronary syndrome (ACS) can be unstable angina, non-ST elevation myocardial infarction (NSTEMI) or ST elevation myocardial infarction (STEMI) [1, 3].

Obstructive sleep apnoea (OSA) is a common comorbidity in patients with ACS. There is increasing evidence that sleep disordered breathing is a risk factor for CAD [4, 5]. In the early phase after STEMI and NSTEMI, the heart may be in a vulnerable state, sensitive to the negative consequences of OSA, including increased cardiac workload [6] and endothelial dysfunction [7], which may ultimately lead to a mismatch between oxygen demand and supply. Despite successful percutaneous coronary intervention, patients with STEMI/NSTEMI and OSA, compared with those without OSA, have prolonged myocardial ischaemia [8], less salvaged myocardium [9], and impaired left and right ventricular remodelling [10, 11], all of which predispose to the development of heart failure [5, 12]. In addition, in patients undergoing percutaneous coronary intervention (the majority due to ACS), OSA is a significant risk factor for major adverse cardiac and cerebrovascular events (MACCEs) [13].

In this context, DE BATLLE et al. [14] aimed to build a predictive model for OSA in a sample of patients with ACS ( $\mathrm{n}=978 ; 12 \%$ unstable angina, 48\% NSTEMI and 40\% STEMI). This analysis was an ancillary study of the randomised controlled ISAACC trial (NCT01335087), evaluating the effect of continuous positive airway pressure (CPAP) treatment on the incidence of new cardiovascular events in patients with an episode of ACS and OSA [15]. The present analysis included patients with OSA, assessed with polygraphy 24-72 $\mathrm{h}$ after admission [14] and defined as $\leqslant 50 \%$ of central apnoeas and an apnoea/hypopnoea index $(\mathrm{AHI}) \geqslant 15$ per $\mathrm{h}$ recording time; patients with $\mathrm{AHI}<15$ per h served as the control group. An unknown number of patients with ACS and predominant central sleep aopnoea were excluded [14].

The final adjusted logistic regression models attempting to predict OSA (AHI $\geqslant 15$ per $\mathrm{h}$ and AHI $\geqslant 30$ per $\mathrm{h}$, respectively) could not establish a prediction model that would justify a validation study (AHI $\geqslant 15$ per $h: R^{2}=0.09$; sensitivity $94 \%$ and specificity $24 \%$; $A H I \geqslant 30 \cdot h^{-1}: R^{2}=0.072$; sensitivity $31 \%$ and specificity $86 \%)$. Significant independent modulators of OSA (AHI $\geqslant 15$ per $\mathrm{h}$ ) were age, body mass index (BMI),

Received: Dec 242016 | Accepted: Jan 032017

Support statement: M. Arzt received research grants and lecture fees from ResMed (Martinsried, Germany) and Philips Respironics (Murrysville, PA, USA).

Conflict of interest: Disclosures can be found alongside this article at erj.ersjournals.com

Copyright CERS 2017 
Epworth Sleepiness Scale, intake of calcium antagonists and peak troponin levels, while for OSA (AHI $\geqslant 30$ per $\mathrm{h}$ ) they were age, BMI, triglycerides, peak troponin and Killip class >I [14].

The majority of the reported patient population had NSTEMI or STEMI [14]. During the first 24-72 $\mathrm{h}$ after the event, the likelihood is high that subclinical pulmonary congestion was present. During this early phase after NSTEMI or STEMI, the predominant type of sleep-disordered breathing is approximately 50\% OSA and 50\% central sleep apnoea [16]. In a significant proportion of patients with ACS, left ventricular function recovers after guideline-conforming treatment of ACS. Patients whose left ventricular function improves after NSTEMI or STEMI often experience a significant alleviation of their sleep-disordered breathing and OSA [16, 17]. Thus, when interpreting the predictive models reported by DE BATLLE et al. [14], one should take into account that polygraphy between 24 and $72 \mathrm{~h}$ after an ACS may be a snapshot of the severity and type of the sleepdisordered breathing and that this may vary considerably afterwards.

In accordance with previous literature, patients presenting with both cardiovascular/cerebrovascular disease and OSA have often no typical clinical presentation helping to clinically suspect OSA, e.g. patients with stroke [18], heart failure [19] or NSTEMI/STEMI ACS [13] usually do not report daytime sleepiness. The association of daytime sleepiness and BMI with the occurrence of OSA appears to be weaker compared with observations in community samples without known cardiac disease [14, 20].

The data reported by DE BATLLE et al. [14] emphasise that in patients with cardiac disease, modulators reflecting the severity of cardiac impairment, e.g. New York Heart Association functional class in patients with heart failure [21], or peak troponin and Killip class $>1$ in patients with ACS [14], are associated with the presence of sleep-disordered breathing. Ultimately, in patient populations with cardiovascular disease, predictive models for sleep-disordered breathing are too weak to be implemented in clinical practice and failed to show proof of potential contributing to clinical and cost-efficient identification patients with sleep-disordered breathing [14, 21, 22].

In a large sample of patients with ACS and OSA or no sleep-disordered breathing, while excluding patients with central sleep apnoea, DE BATLLE et al. [14] could not establish a prediction model with sufficient sensitivity and specificity that would justify a validation study before clinical use. Thus, in such patient populations, monitoring of sleep-disordered breathing has to be performed in order to identify patients with ACS and comorbid OSA. Further evidence from randomised controlled trials (ISAAC, NCT01335087; TEAM-ASV I, NCT02093377) may help elucidate whether OSA should be identified early after ACS or whether routine diagnosis should be performed after the optimal treatment for ACS and ACS-related heart failure is established.

\section{References}

1 Steg PG, James SK, Atar D, et al. ESC Guidelines for the management of acute myocardial infarction in patients presenting with ST-segment elevation. Eur Heart J 2012; 33: 2569-2619.

2 WHO. Fact sheet N8310. www.who.int/mediacentre/factsheets/fs310/en/index.html Date last updated: May 2014. Date last accessed: December 2016.

3 Roffi M, Patrono C, Collet J-P, et al. 2015 ESC Guidelines for the management of acute coronary syndromes in patients presenting without persistent ST-segment elevation: Task Force for the Management of Acute Coronary Syndromes in Patients Presenting without Persistent ST-Segment Elevation of the European Society of Cardiology (ESC). Eur Heart J 2016; 37: 267-315.

4 Lévy P, Kohler M, McNicholas WT, et al. Obstructive sleep apnoea syndrome. Nat Rev Dis Primers 2015; 1: 15015.

5 Arzt M, Hetzenecker A, Steiner S, et al. Sleep-disordered breathing and coronary artery disease. Can J Cardiol 2015; 31: 909-917.

6 Hetzenecker A, Buchner S, Greimel T, et al. Cardiac workload in patients with sleep-disordered breathing early after acute myocardial infarction. Chest 2013; 143: 1294-1301.

7 Sert Kuniyoshi FH, Singh P, Gami AS, et al. Patients with obstructive sleep apnea exhibit impaired endothelial function after myocardial infarction. Chest 2011; 140: 62-67.

8 Nakashima H, Muto S, Amenomori K, et al. Impact of obstructive sleep apnea on myocardial tissue perfusion in patients with ST-segment elevation myocardial infarction. Circ J 2011; 75: 890-896.

9 Buchner S, Satzl A, Debl K, et al. Impact of sleep-disordered breathing on myocardial salvage and infarct size in patients with acute myocardial infarction. Eur Heart J 2014; 35: 192-199.

10 Buchner S, Eglseer M, Debl K, et al. Sleep disordered breathing and enlargement of the right heart after myocardial infarction. Euro Respir J 2015; 45: 680-690.

11 Nakashima H, Katayama T, Takagi C, et al. Obstructive sleep apnoea inhibits the recovery of left ventricular function in patients with acute myocardial infarction. Eur Heart J 2006; 27: 2317-2322.

12 Aronson D, Nakhleh M, Zeidan-Shwiri T, et al. Clinical implications of sleep disordered breathing in acute myocardial infarction. PLoS One 2014; 9: e88878.

13 Lee C-H, Sethi R, Li R, et al. Obstructive sleep apnea and cardiovascular events after percutaneous coronary intervention. Circulation 2016; 133: 2008-2017.

14 de Batlle J, Turino C, Sánchez-de-la-Torre A, et al. Predictors of obstructive sleep apnoea in patients admitted for acute coronary syndrome. Eur Respir J 2017; 49: 1600550.

15 Esquinas C, Sánchez-de-la Torre M, Aldomá A, et al. Rationale and methodology of the impact of continuous positive airway pressure on patients with ACS and nonsleepy OSA: the ISAACC Trial. Clin Cardiol 2013; 36: 495-501. 
16 Buchner S, Greimel T, Hetzenecker A, et al. Natural course of sleep-disordered breathing after acute myocardial infarction. Eur Respir J 2012; 40: 1173-1179.

17 Randerath W, Verbraecken J, Andreas S, et al. Definition, discrimination, diagnosis and treatment of central breathing disturbances during sleep. Eur Respir J 2017; 49: 1600959.

18 Arzt M, Young T, Peppard PE, et al. Dissociation of obstructive sleep apnea from hypersomnolence and obesity in patients with stroke. Stroke 2010; 41: e129-e134.

19 Arzt M, Harth M, Luchner A, et al. Enhanced ventilatory response to exercise in patients with chronic heart failure and central sleep apnea. Circulation 2003; 107: 1998-2003.

20 Arzt M, Young T, Finn L, et al. Sleepiness and sleep in patients with both systolic heart failure and obstructive sleep apnea. Arch Int Med 2006; 166: 1716-1722.

21 Arzt M, Woehrle $\mathrm{H}$, Oldenburg $\mathrm{O}$, et al. Prevalence and predictors of sleep-disordered breathing in patients with stable chronic heart failure: The SchlaHF Registry. JACC Heart Fail 2016; 4: 116-125.

22 Parisot J, Damy T, Gellen B, et al. Sleep-disordered breathing in chronic heart failure: development and validation of a clinical screening score. Sleep Med 2015; 16: 1094-1101. 